\title{
Portraits of Activism: ACT-UP in Retrospect
}

\author{
Martin C. McElhiney 1,2*, Judith G. Rabkin ${ }^{1,2}$, Madeline R. Finkel ${ }^{1}$, Tim Horn ${ }^{3}$, Mark Harrington 4
}

${ }^{1}$ New York State Psychiatric Institute, New York, USA

${ }^{2}$ Department of Psychiatry, Columbia University, New York, USA

${ }^{3}$ National Alliance of State and Territorial AIDS Directors, Washington, DC, USA

${ }^{4}$ Treatment Action Group, New York, USA

*Corresponding Author: mcelhin@nyspi.columbia.edu

Citation: McElhiney, M. C., Rabkin, J. G., Finkel, M. R., Horn, T. and Harrington, M. (2020). Portraits of Activism: ACT-UP in Retrospect, Journal of Cultural Analysis and Social Change, 5(1), 04. https://doi.org/10.20897/jcasc/6362

Published Online: December 11, 2019

\begin{abstract}
We present members' recollections of their ACT UP participation from the early years of the AIDS epidemic. ACT UP had a major impact on public opinion, government action, and the design and conduct of clinical trials. While the historical setting was distinctive, lessons can be learned for contemporary social movements.

We interviewed 125 members of ACT UP, using a semi-structured interview including both scales and openended queries. We asked the following: Why did they join? What did they do? Why did they leave? What do they most miss? What were the best and most difficult aspects? Major findings include the following: Members sought, and found a community of like-minded people sharing a primary goal: to find treatments and end the epidemic. In terms of what they missed, many spoke of the camaraderie, support and group cohesion.

Communication choices have expanded since the early days of ACT UP's weekly meetings; new technologies have multiplied. Nevertheless, ACT UP remains a model in terms of its sustained local social networks, publicity-generated attention to a focused agenda, meticulous preparations for actions and public relations, and educated recommendations for solutions. Inclusion of voices of those whose welfare is at issue can be a powerful tool for change.
\end{abstract}

Keywords: ACT UP, activism, collective action, AIDS, social networks

\section{INTRODUCTION}

In the 1980s, a new, lethal, and stigmatized disease was rapidly spreading in the United States, predominantly among gay men, injecting drug users, and blood donor recipients. In response to public opprobrium and government indifference, an activist movement was founded to fight both: the AIDS Coalition to Unleash Power, or “ACT UP." Its years of peak impact were 1987-1992. In a previous report (Rabkin, McElhiney, Harrington and Horn, 2018), we presented findings from interviews, including standardized measures for assessment, with 125 former ACT UP/New York members, during which we examined trauma sequelae as well as post-traumatic growth. We now describe interviewees' experiences and memories from those years, using their voices, to add to the literature on participatory social movements and social change. Perhaps lessons can be learned that may inform contemporary activists seeking to influence public opinion and government policy.

The incentive to undertake this project has been a growing awareness that members of the New York flagship chapter of ACT UP had participated in an extraordinary movement. ACT UP was a highly visible and influential 
advocacy group, evolving from a tradition of civil disobedience; multiple chapters soon were established nationally and overseas. Participation generally included protracted exposure to conflict (both ideational and physical), and had dramatic impact on government policy and research, increase in services such as AIDS-related medical care, housing, and health insurance. In the process, ACT UP altered the perception of the LGBTQ community, both of its members and the general public. Today, those who were engaged in the early years are all "long-term AIDS survivors," whether HIV+ or not.

\section{BACKGROUND}

ACT UP was formed in March 1987 at what was originally called the Lesbian and Gay Community Services Center. The meeting attracted "a large crowd of mostly gay men - the curious, the frightened, and the furious," as Crimp with Rolston noted (1990: 27). Some came to the group with experience in activism from participation in the gay or women's rights movements or in early AIDS activist groups (e.g. the Lavendar Hill Mob), while others were completely new to activism. Others had experience with AIDS through volunteering at service or advocacy organizations such as the Gay Men's Health Crisis (GMHC), which was founded in 1982 (Kayal, 1993). Its initial rallying cry was, "Drugs into Bodies," referring to the desperate need for effective and accessible medications (France, 2016). Following traditions of earlier activist groups, its central characteristic was to be "a democratic, open group committed to direct action as a means of ending the AIDS crisis" (Smith and Siplon, 2006, p. 26). It had no formal structure, spokesperson or permanent director. During its peak years, there was a general Monday meeting attended by hundreds (Rimmerman, 1998). All plans, demonstrations, budgets and even signs and tee shirt designs were discussed (often at length) at these meetings, and approved or rejected by majority vote by those members who had attended three or more meetings (Slezak, 2008; Smith and Siplon, 2006). Standing committees handled ongoing needs and functions, such as finance, media, graphics, and legal resources. Others were contentbased (e.g. Needle Exchange, Treatment and Data, Youth Education Life/Line [YELL], and Housing). A third type represented specific groups (e.g. Latino/a Caucus, Majority Actions, Women's Caucus). Many members were active in initiating and preparing for demonstrations, sometimes in small affinity groups, while some remained on the periphery, self-described as "foot soldiers." Although numerically fewer, women played an important role. As Cvetkovich (2003) noted, "The lesbians in ACT UP had a crucial and visible role, disproportionate to their numbers, because so many of them came to ACT UP with previous political experience and contributed organizing skills" (p. 174). While actively involved in all major demonstrations, committees and affinity groups, they were particularly focused on women and AIDS, effectively changing the CDC definition of AIDS to include infections specific to women.

ACT UP was known for its confrontational but non-violent demonstrations ("actions, demos, zaps"), in New York City, Washington D.C. and elsewhere. They were intended to protest, bear witness, and target political enemies in order to bring attention to key issues (Evans, 2016). Overall, targets were selected, actions were carefully planned, and follow-up was provided for both participants and media representatives.

Some members of one of ACT UP's subgroups, Treatment and Data, left in January 1992 to form a new organization, Treatment Action Group (TAG). Their departure was a culmination of ongoing disagreement about strategies and tactics; the activist and research wings parted ways (Crewe, 2018). Other committees already had spun off to pursue focused agendas, becoming Housing Works and the Needle Exchange Program. By then, initial progress for people with AIDS had been made in terms of access to health insurance and medical care, approval of a few drugs to treat or prevent HIV-related infections, housing, passage of the Ryan White CARE Act in 1990, and both local and national acknowledgement of the epidemic as such. However, deaths continued to escalate, and no cure was in sight.

ACT UP has continued to the present, with a substantially lower profile, a fraction of the size, and fewer large public events. Seven men in our sample continued to be active members when interviewed. Recently, ACT UP New York has been focusing on the New York State plan to End AIDS by 2020, issues of long-term survivors, uptake of pre-exposure prophylaxis (PrEP), and policies and strategies to address escalating methamphetamine use in the local community.

For this project, we interviewed former ACT UP members to address the following questions: 1) Why did they join ACT UP? 2) What did they do as members? 3) Why did they leave; 4) Since leaving ACT UP, do they miss anything? 5) What were the most rewarding ("positive") and most difficult aspects of membership? 


\section{METHODS}

\section{Design of Questionnaire}

As described elsewhere (Rabkin, McElhiney, Harrington and Horn, 2018), we constructed a semi-structured interview and developed code sheets. Format included both checklists and open-ended questions, developed on the basis of pilot interviews with key informants (mental health professionals prominent in HIV research or treatment, and a former ACT UP member) as well as feedback from a community advisory board, all of whom were former ACT UP members. Two of the authors (MMc and MH) were members of ACT UP. The interview covered background information, ACT UP participation between 1987-1992, and current work, social ties, health and mental health. Interviews lasted about 90 minutes (the consent form was sent by e-mail in advance). In addition, six validated self-report scales were administered; these results were reported earlier (Rabkin, McElhiney, Harrington and Horn, 2018). Our study included only members of ACT UP/New York.

\section{Data Analyses}

Quantitative analyses included t-tests and chi square analyses. With a mixed-methods approach, we used both open-ended queries and checklists. For analysis of qualitative data, we used the method of Consensual Qualitative Research developed by Hill and colleagues (2012) to categorize the content of the spontaneous responses. The first step was to identify broad domains that emerged in the responses and to create possible categories. Three independent raters then assigned responses to the categories and met to reconcile discrepancies, if any, in their classifications. Responses are presented according to category on Tables 2-4 for the categories that included greater than $10 \%$ of responses, other categories with their respective responses are not shown. For the four checklists, we compared responses by gender, by HIV status (men only), and by age (using a median split of 28). Only statistically significant results are reported $(\mathrm{p}<.01)$.

For queries that include both open ended responses and checklists (why they joined, what they miss, and "positive" aspects of ACT UP), we present open-ended responses both in the text and then by category of response. The checklist responses are presented in bar graphs. For the query about why they left, we did not include an open-ended query so results are presented in a bar graph alone. For the query about "What was difficult about being an ACT UP member", for which there was no checklist, we present illustrative examples of the most common responses based on qualitative scoring alone (Table 5). The verbatim excerpts, often vivid, are included to amplify the quantitative findings. Tables 2-5 are organized by themes emerging from qualitative analyses, independent of the checklists.

\section{PROCEDURES}

\section{Recruitment Methods}

There was no official membership list, and no way to obtain a random sample of survivors. Instead, using purposive and snowball sampling, outreach was conducted by former ACT UP members, including co-authors and colleagues, and members of a community advisory board, who contacted others and posted notices on the ACT UP Alumni Facebook page. Local participants were interviewed in person, while 26\% (N=33), living in 14 other states and 3 foreign countries were interviewed by telephone, with consent forms and self-reports sent by email or fax.

The study was approved by the New York State Psychiatric Institute-Institutional Review Board. Interviews were conducted between June 2013 and March 2015. All participants provided written informed consent after the risks and benefits of study participation were discussed and any questions addressed.

\section{RESULTS}

\section{Sample}

We interviewed 125 former ACT UP members, including 102 men and 23 women (demographics are shown in Table 1). All but one in each group identified as gay. Sixteen men (15\%) were people of color, as were three women. Mean age when joining ACT UP was 28 (median = 28, range =13-50). When interviewed, 41 men (no women) were HIV+. Of those who were HIV+, $29 \%(\mathrm{~N}=12)$ already knew it when they joined. An additional $41 \%(\mathrm{~N}=17)$ learned their HIV+ status while members, and 29\% ( $\mathrm{N}=12)$ tested positive after 1992.

When interviewed, $80 \%$ of respondents were working full-time or part-time, $12 \%$ were receiving disability benefits or were unemployed. The range of current income ranged from under $\$ 15,000(10 \%$, usually on disability or public assistance) to over $\$ 100,000(18 \%)$. Eighty-five percent had college or graduate degrees. 
Table 1. Current demographic characteristics

\begin{tabular}{|c|c|c|c|c|}
\hline & $\begin{array}{c}\text { Male HIV+ } \\
\mathrm{N}=41\end{array}$ & $\begin{array}{c}\text { Male HIV- } \\
\mathrm{N}=61\end{array}$ & $\begin{array}{c}\text { Female* } \\
N=23\end{array}$ & $\begin{array}{c}\text { Total } \\
\mathrm{N}=125\end{array}$ \\
\hline Age, M (Range) & $55(45-73)$ & $54(44-74)$ & $52(37-68)$ & $54(37-74)$ \\
\hline \multicolumn{5}{|l|}{ Ethnicity, N (\%) } \\
\hline White & $35(85)$ & $51(84)$ & $20(87)$ & $106(85)$ \\
\hline Black & 0 & $2(3)$ & $3(13)$ & $5(4)$ \\
\hline Hispanic & $6(15)$ & $7(11)$ & 0 & $13(10)$ \\
\hline Other & 0 & $1(2)$ & 0 & $1(1)$ \\
\hline \multicolumn{5}{|l|}{ Education, N (\%) } \\
\hline Less than college & $7(17)$ & $9(15)$ & $3(13)$ & $19(15)$ \\
\hline College & $15(37)$ & $25(38)$ & $7(30)$ & $47(38)$ \\
\hline Graduate training & $19(46)$ & $27(44)$ & $13(57)$ & $59(47)$ \\
\hline \multicolumn{5}{|l|}{ Income, N (\%) } \\
\hline Under $\$ 30,000$ & $11(28)$ & $13(22)$ & $5(22)$ & $29(24)$ \\
\hline $30,000-75,000$ & $14(35)$ & $22(37)$ & $9(39)$ & $45(36)$ \\
\hline $76,000-99,999$ & $4(10)$ & $11(18)$ & $3(13)$ & $18(15)$ \\
\hline$\$ 100,000+$ & $11(27)$ & $14(23)$ & $6(26)$ & $31(25)$ \\
\hline
\end{tabular}

*All HIV-

Table 2. Why did you join ACT UP?

Personal and collective action about the AIDS Epidemic

Being in ACT UP changed the epidemic from something that was happening to me to something I could do about it. I have political agency. I can fight for beliefs.

Fury, desperation. It seemed like I had to. I liked the militancy of it and the attention it was getting and the effect it was having.

To identify as an AIDS activist, a different identity that was strong, tough. I felt at the point of a spear.

No way I could stand by and not do something when all my friends were dying.

This was the most exciting phenomenon in the gay community. In the midst of a genocidal epidemic, how could I not be involved?

\section{The People}

It was the most vital group of people I'd ever seen. Entrance table was full of literature and there was a buzz everywhere.

I admired the strength and image of faggots DOING something for themselves.

I went to a meeting and it was the most compelling thing I was ever introduced to. The energy in the room, the way it worked.

The meetings were amazing ... attractive, articulate people talking about what needs to be done!

Getting to be around some of the most brilliant minds of our age. Realizing ideas - conceiving large ideas and making them happen.

Camaraderie/Community

I was at the community center and went to a meeting. It was like a religious experience. It was a feeling, a deep sense of community.

I was looking for a gay community. To find people I could be gay with. And I found the meetings the most intense experience I ever had. So much energy in the room.

Friend brought me. I walked into that room and I suddenly got permission to be angry. It was a brotherhood, falling in love with and protecting each other. Everyone's back was covered.

I was young and afraid and seeking a community.

They helped me come out. I belonged there. I was home. They took my fear. I was scared since 1985.

Anger at the Government and Public Indifference

I was filled with rage about homophobia and AIDS and completely embraced the ideology of ACT UP.

A combination of Koch + Reagan. We saw that the disaster was not represented in the media in the full force of the disaster.

At meetings, the energy was unbelievable. I thought, 'these guys have their shit together.' They seemed to be kicking butts; we were angry about the political climate. The goal was to wake up the country and leadership.

I stayed with ACTUP because it was a groundswell of support to bring our anger to the media.

Anger at Reagan and lack of government response. It was the excitement and great pleasure of being with people who felt like I did, outraged at the government, felt we should do something about it.

\section{Life before Joining ACT UP}

Before joining ACT UP, 68\% of respondents were working full-time, $13 \%$ part-time, and $19 \%$ were in school. More men had jobs ( $73 \%$ vs. $34 \%)$ while more women were in school $\left(43 \%\right.$ vs. $\left.10 \%, \mathrm{X}^{2}=21.41,3 \mathrm{df}, \mathrm{p}>.001\right)$. Most (74\%) previously had been engaged in activist groups (e.g. anti-war, civil rights, feminist) or community groups (e.g. lesbian-gay college clubs) with a trend for more women than men to have had such prior experience $\left(\mathrm{X}^{2}=3.33,1 \mathrm{df}, \mathrm{p}=.07\right)$.

\section{ACT UP Years}

\section{Why did they join?}

Respondents were asked an open-ended question about why they joined ACT UP, and then were offered a checklist of six possible reasons (they could select more than one). For example, one respondent said, "It was the single most important thing I could do. We were in the middle of a holocaust and these people were trying to fix 


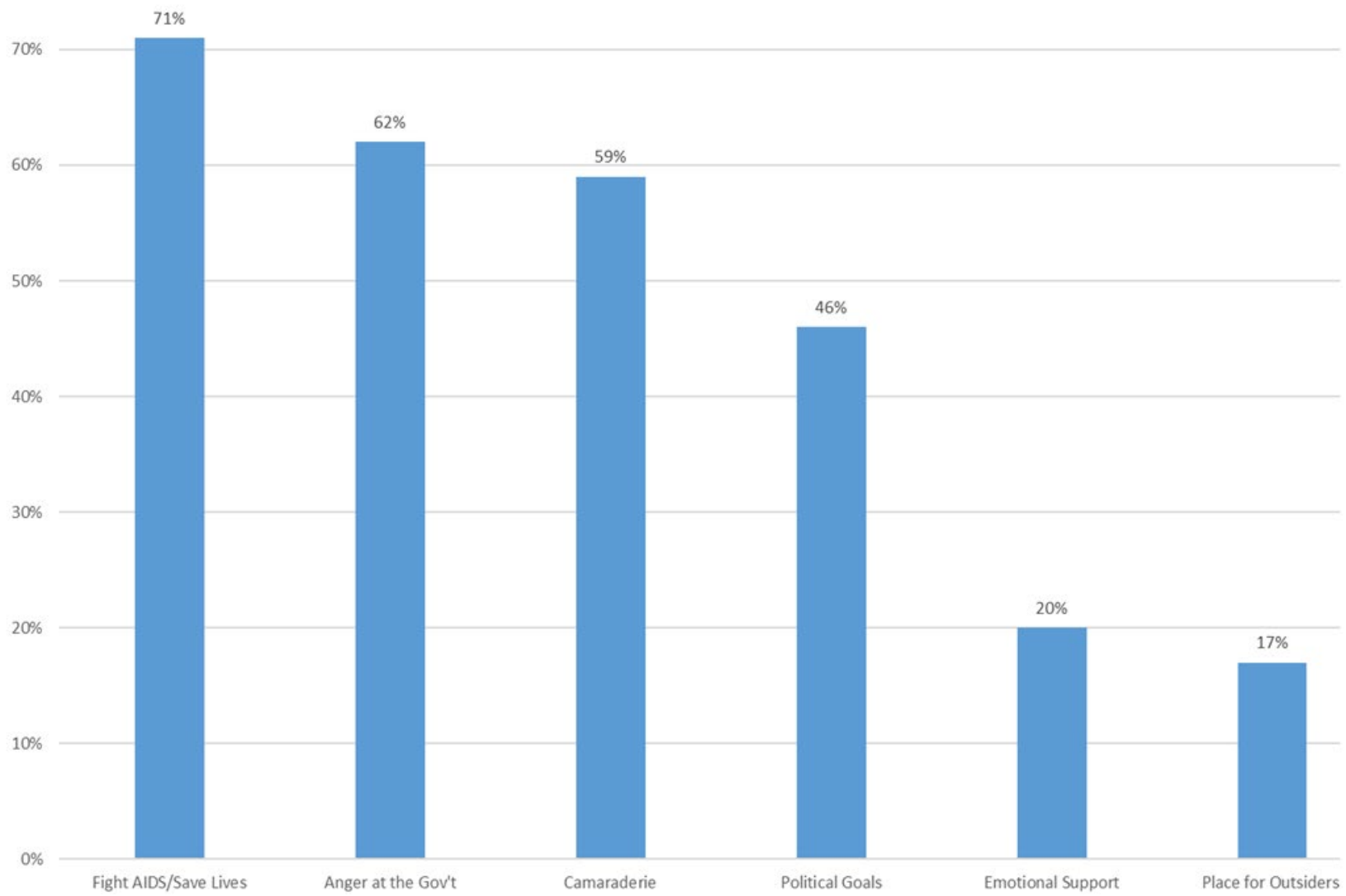

Figure 1. What made you decide to join ACT UP?

it." Another said, "My friends were dying and I was grieving. [In ACT UP] I could take this and put it into anger... It was die or do something." And another: "Witnessing incredibly disparate people coming together and forming a coalition focused on a practical goal" (other open-ended responses are shown in Table 1).

On the checklist, 71\% (89/125) endorsed Fighting AIDS/Finding treatment/Saving lives (see Figure 1). Other reasons for joining included Anger at the government [for lack of attention to AIDS] (62\%) and Political goals (such as justice, bealth access equity, gay and minority rights) (46\%). Political goals was endorsed more often by women $(74 \%)$ than men $\left(40 \%, \mathrm{X}^{2}=14.18,1 \mathrm{df}, \mathrm{p}=.001\right)$. Camaraderie was endorsed by $59 \%$, more often by younger $(71 \%)$ than older members $\left(45 \%, \mathrm{X}^{2}=8.9,1 \mathrm{df}, \mathrm{p}=.003\right)$. Emotional support motivated $20 \%$, more often by HIV+ than HIV- men $\left(\mathrm{X}^{2}=14.18,1 \mathrm{DF}, 0=.001\right)$. One motive for joining we had not anticipated (and thus did not include in the checklist) emerged from the qualitative responses: The people. For example, one respondent explained, "When I saw the passion and brilliance in the room, I knew I had to join."

\section{What did they do?}

We asked about degree of their engagement between 1987 and 1992, attendance at the main Monday meeting, participation in demonstrations and actions, arrests, and involvement in standing committees. In addition, we asked about the personal experience of the epidemic.

Average duration of participation (for the 118 study participants who had left ACT UP) was 4.3 years (SD = 1.83). Eighty-five percent of members joined before 1990 and 78\% left before 1993.

Interviewees were asked to rate the frequency of their attendance at Monday meetings and were given the choice of: Regularly, Often, Occasionally or Rarely. The overwhelming majority (115/125, 92\%) indicated attending Regularly (one member observed, "it was like going to Mass"). Ninety-eight percent (122/125) took part in demonstrations: $87 \%(109 / 125)$ in more than 10 , and another $10 \%(12 / 125)$ participated in 5 to 10 demonstrations. Seventy percent $(87 / 125)$ were arrested at least once while demonstrating, including $55 \%$ arrested more than once. Committees had various functions and time commitments; $81 \%$ of our study members $(\mathrm{N}=101)$ belonged to at least one. Other activities also occurred under the ACT UP umbrella, such as a speakers' bureau, ACT UP delegate at AIDS conferences, and a presidential election group.

Against the backdrop of their ACT UP involvement, members were living through the epidemic itself: personal illness, caregiving, funerals of partners, friends, and other ACT UP members. In the 1980s and early 1990s, 30\% 


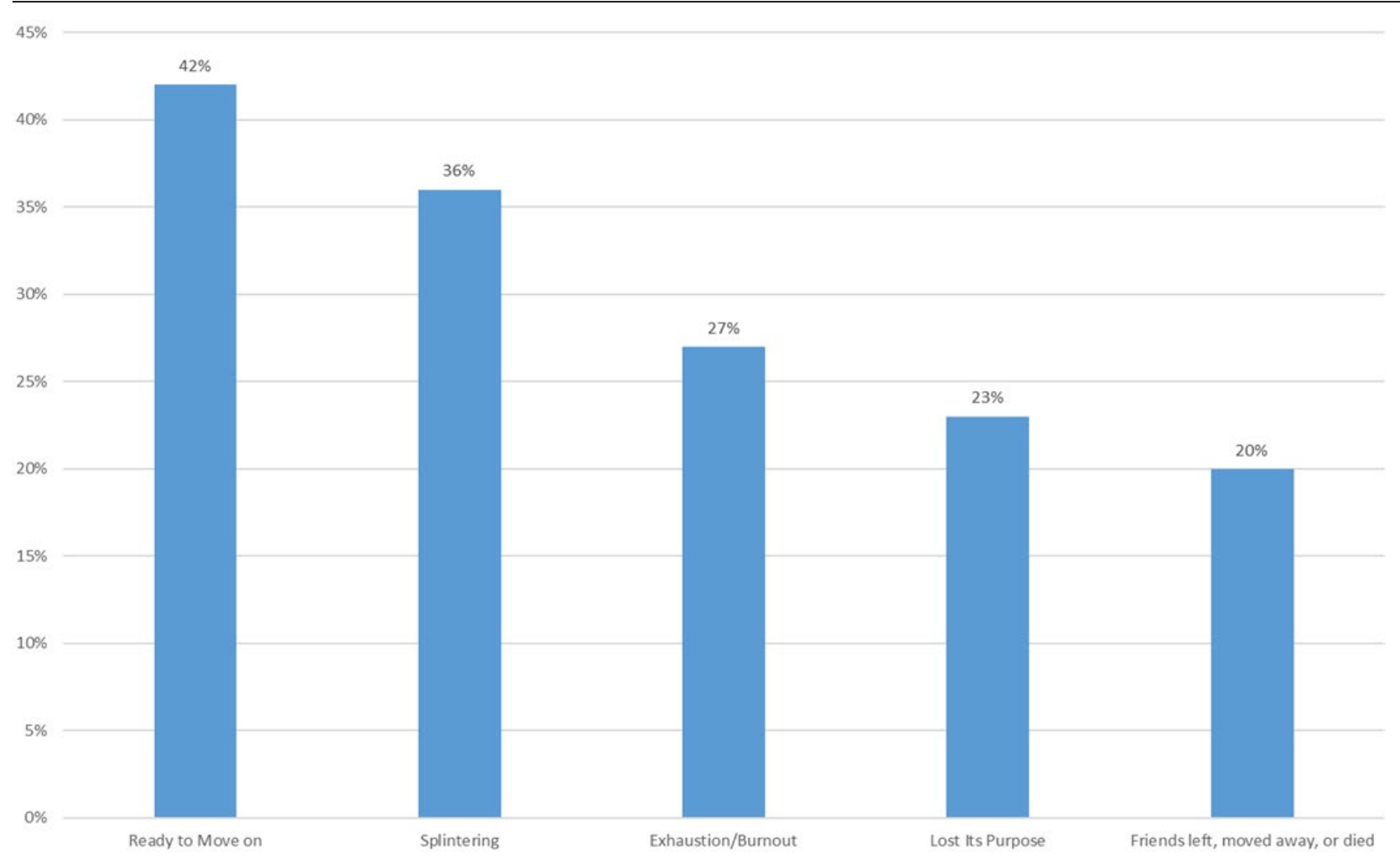

Figure 2. Why did you leave ACT UP?

$(37 / 125)$ of interviewees were primary caregivers for sick partners and friends, and nearly half (61/125) were members of care-giving teams. We asked about the experience of cumulative losses through 1996 when the first effective medications, protease inhibitors, were marketed. Fifty-six (45\%) recalled attending funerals Frequently or Constantly, and $36(29 \%)$ attended funerals Occasionally. Eighty-five participants (68\%) reported losing more than 5 friends to AIDS, and 27 men (26\%) lost a partner.

In short, the vast majority of ACT UP members personally experienced the human costs of the epidemic, and intermingled care-giving, funeral attendance and ACT UP engagement. As one noted, "We lost half our friends, but we were a community and supported each other. It was an awful tradeoff."

\section{Why did they leave?}

When asking about reasons for leaving ACT UP, we offered a seven-item checklist but not an open-ended query. Respondents could endorse more than one reason. The most frequent reasons were Ready to move on (to school, careers, personal lives) $(42 \%)$ and Splintering of the organization (36\%). Other reasons were Exhaustion and burnout (27\%), Lost its purpose, (23\%), and Friends left, moved away or died (20\%) (Figure 2). There were no differences by gender or HIV status, but older members at the time of joining ( $\geq 29$ years old) were more likely than younger members $(<29$ years old $)$ to indicate leaving because Friends left, moved away or died $\left(33 \%\right.$ vs. $12 \%, X^{2}=8.17, \mathrm{p}=$ $.004)$.

\section{After ACT UP}

\section{What do they miss?}

We asked, "Since leaving ACT UP, do you miss anything?" After recording their response, we then offered a check-list. Common themes concerned loss: of a cause, of community, of activism. It is noteworthy that many provided "compound" responses containing more than one theme. For example: "Vibrancy, urgency of illness, the direct impact on changing things, being gay, being an activist. Everything was important - what I wore, what I ate, where I went - everything was a political statement." Another said, "ACT UP was a home. I spent five years many nights a week engaged in a community." Other examples: "I miss the vitality, the ability to do something right away and have it matter. There was energy and clarity in that." Another said, "I miss the collective struggle of large numbers of angry gay people and the creativity, the fierceness" (see Table 3 for additional examples). 
Table 3. Since leaving ACT UP, do you miss anything?

Loss of Community

Tremendously. I never found a community with so much passion, commitment, engagement.

I miss the connection I had with people in it, the shared understanding of what was wrong with the world and how to fix it. And the passion I had at the time.

I miss the sense of community. After college, it was the only time in my life when I belonged to a community. I felt connected to people which was by far the best thing about it.

Friendships, relationships, the sense we were doing something significant and making changes, moving forward and doing and succeeding and community involvement.

\section{Loss of a Cause}

Yes, totally - I miss a sense of mission - life has seemed bland since. Nothing else has compared.

Everything was so clear then - Black and white - Good and evil. We were so clear - I miss it. It made the world easy to negotiate. I also miss the excitement.

The sense of accomplishment, making things happen, working with friends. Was probably one of the high points of my life in terms of community and doing something that matters.

Everything. Loss of a cause, friendships. There was a kind of fulfillment. I was so young, 22, when I joined. It was the most optimistic thing I've ever done in terms of making a difference in the world.

\section{Activism}

Yes. It was a time when everyone cared about the same thing; that sense of being part of radical politics, and the sense of danger- now I have such a stable middle class life I can't imagine being arrested.

I miss being part of a group of people who with concentrated effort, planning and bravery can make a difference. It's a kind of nostalgia. I miss it because I forget the difficult aspects.

Yes, the teamwork, the socialization. We would gather on a street corner before a demonstration, would do the demo, do support, go out together afterwards.

I miss the collectivism, the fight, the commitment.

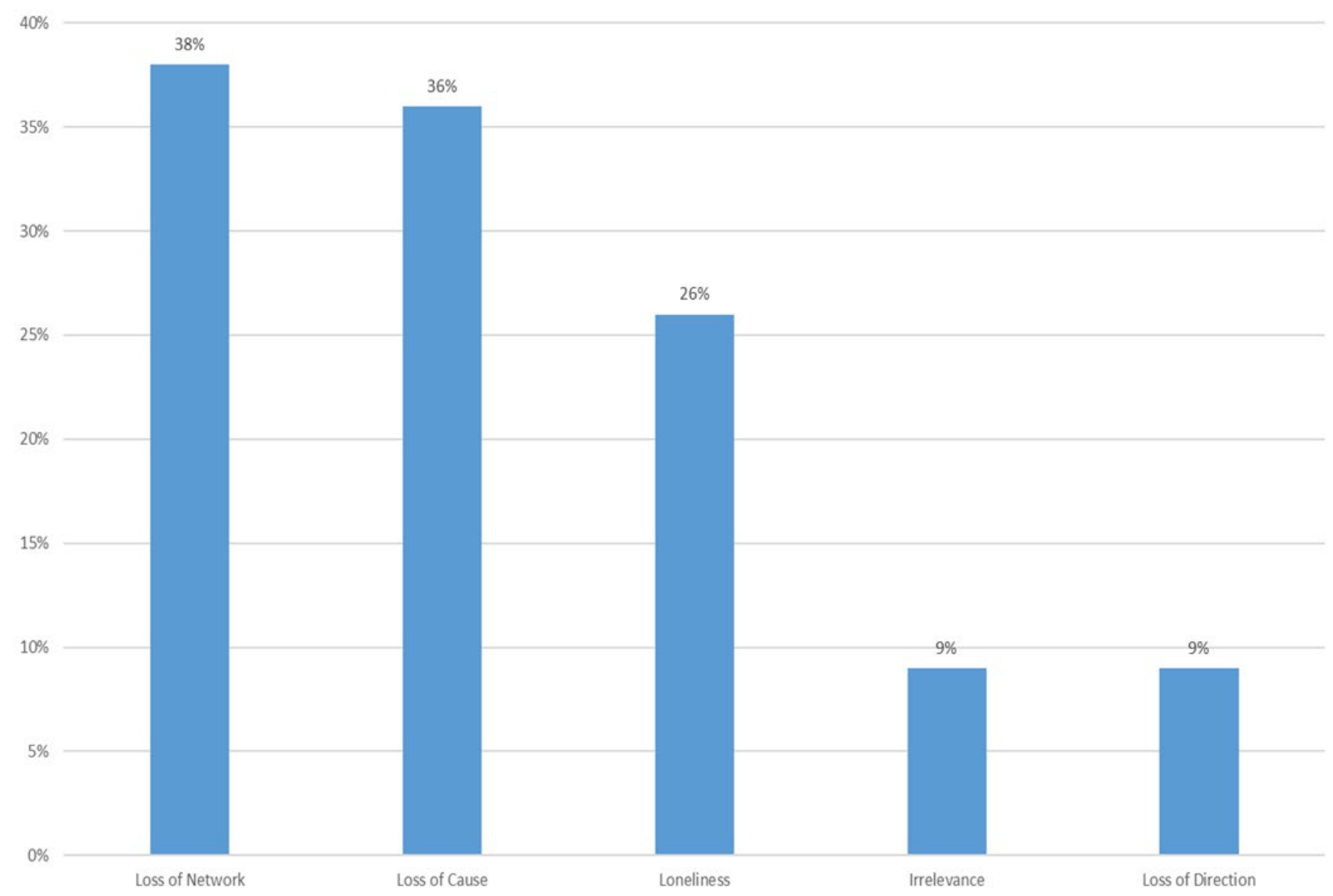

Figure 3. Since leaving ACT UP, do you miss anything?

On the six-item checklist, of the 118 members who left, Loss of network (38\%) and Loss of a cause (36\%) were the most frequently endorsed. A related reason was Loneliness $(26 \%)$. No other reason was cited by more than $9 \%$ of respondents (see Figure 3). There were no differences in response associated with age, gender or HIV status.

A significant minority $(25 / 118=21 \%)$ said they did not miss their ACT UP years. For example: "I still felt connected to activism. I took ACT UP with me. It never left me." Another, with less positive memories, said, "Not really. We lacked the capacity for self-criticism. The epidemic changed but ACT UP didn't evolve." Others: "I needed to move on and get away from death," or simply, "no." 
Table 4. In what ways was ACT UP a positive experience?

Community

Incredible sense of community: like-minded, angry, ready to take on the Powers That Be.

An incredible sense of camaraderie, being part of an army trying to change the world. I was a participant in an activist community in a time of community crisis.

It made me proud to belong to this community: people were doing something meaningful, not just fuck, drugs, die.

A sense of being part of the gay community. I was no longer alone and isolated.

Cathartic benefit of collective - to dispel fear, grief, rage, and to see the impact and change.

\section{Saving Lives/Making a Difference}

Being part of the process to get drugs and treatment for people, we knew would save lives.

We were doing something concrete. We were productive in terms of accelerating the scientific process.

Making a difference in the outside world and feeling like we saved lives.

Because of the crisis it was pragmatic and focused on real problems with real results.

It was so damn effective.

Personal growth

I found my voice and the courage to act in spite of fears - a tremendous sense of empowerment.

It showed me how I can be my best me. Now I don't have anything to prove to anyone.

ACT UP forced me to confront HIV despite my fear of death, and that was empowering.

It pushed the limits of how much I could be involved in activism - it pushed my limits of what I was able to do.

Empowerment. It taught me I could do things I had no idea I could do.

\section{Most Rewarding? Most difficult? Recall of Consequences}

\section{Rewarding aspects}

We asked, "In what ways was ACT UP a positive experience?" First we recorded spontaneous answers, and then offered a checklist of options. For the former, the most common theme for positive aspects of membership concern Community (Table 4). One respondent said, "Just to be with people who 'got' what I was experiencing, who knew what it was like to feel you're on a conveyer belt leading to the grave and not knowing how near you are to the end of the belt." Other examples: "The people I met, being with so many smart, talented people," and "Friendships with people you trusted and who always would be there for you." Similar responses were recorded in queries about "reasons for joining," and "what was missed," as shown in Tables 2 and 3: members found what they came for.

The second general theme was Saving lives/Making a difference, doing something that matters: "Our ability to implement change. It was exciting. We changed the fabric of American culture, medicine, views of LGBT, activism - we changed everything."

A third prominent theme was Personal growth. "ACT UP changed my outlook, my sense of what I could accomplish, my view of the world, view of myself. Empowerment. It taught me I could do things I had no idea I could do. It taught me there are other people like me: smart, spiky, angry, fiercely committed. We had an effect."

Figure 4 shows the percent of responses to the checklist items (more than one could be selected). The most commonly endorsed items largely overlap with the open-ended responses: New or stronger social/community ties with others in ACT UP, Empowerment (personal growth) and Fighting for one's life or one's community survival. Participants who were younger when they joined ACT UP $\left(<29\right.$ years old) were more likely to endorse Social ties $\left(90 \%\right.$ vs. $66 \%$, $\mathrm{X}^{2}$ $=10.61, \mathrm{p}=.001)$ and also Collective identity (83\% vs. $\left.50 \%, \mathrm{X}^{2}=15.11, \mathrm{p}<.001\right)$. 


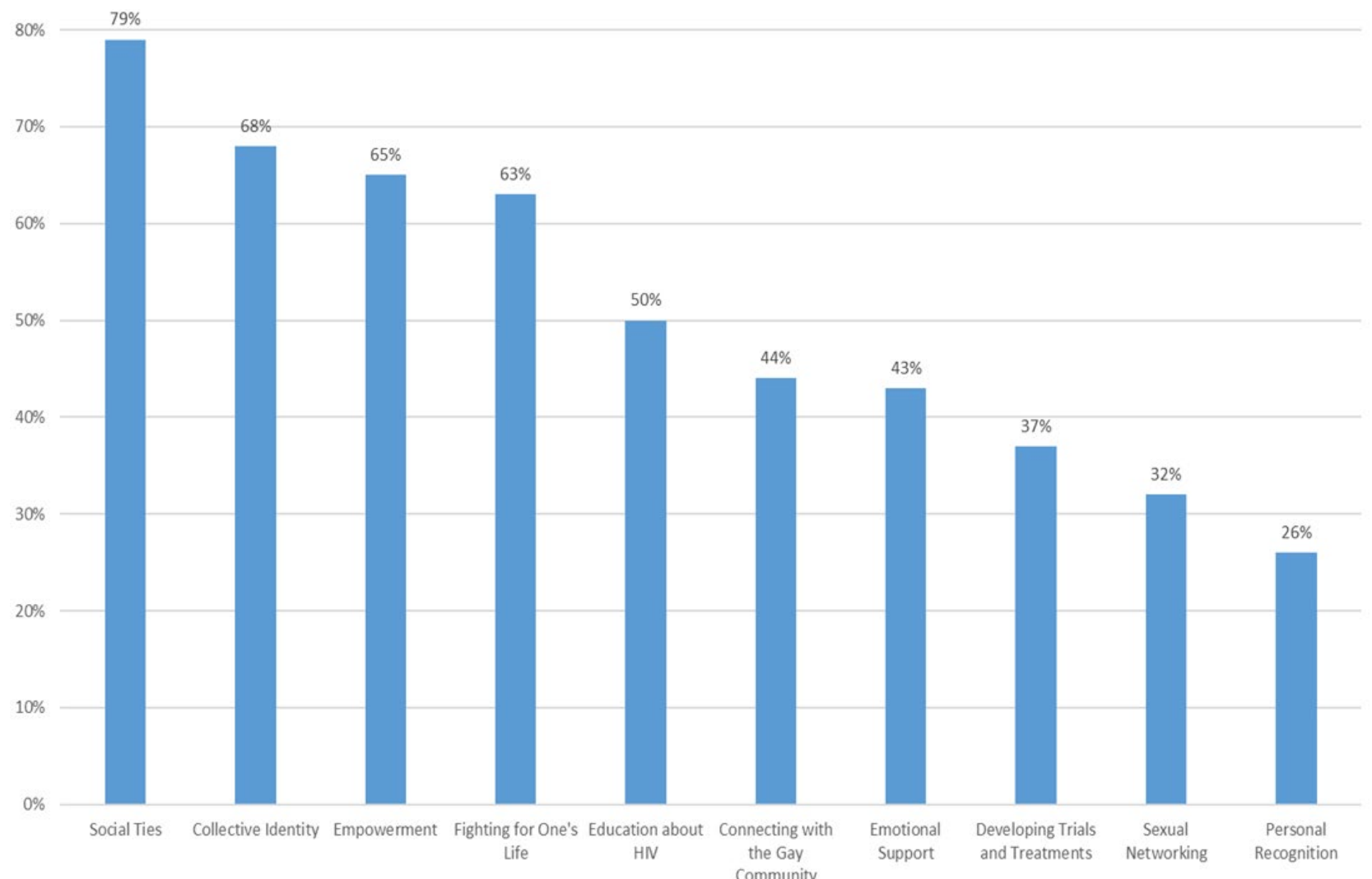

Figure 4. In what ways was ACT UP a positive experience?

Table 5. What was Difficult about being an ACT UP member?

\section{Conflict}

A lot of crazy people screaming.

Lack of negotiating, no effort at consensus, just shouting down differences.

People attacked you viciously if you didn't adhere to the party line.

Persistence of emphasis on "grass roots" style where everything and everyone promoted hugely different agendas.

The unwarranted Monday meeting attacks after an action or demonstration; after putting in so much work.

\section{Loss and Death}

People dying, we couldn't save them, the drugs weren't there.

Watching people die when you're fighting to save their lives.

The losses. Having to tolerate the intolerable. It was emotionally excruciating.

People were sick and dying, and being mad and angry left no time to be sad. We had no energy to be sad.

Overwhelming tide of death.

Time Commitment

My involvement in ACT UP stopped my career because I was so involved in ACT UP.

I had a really hard time with balance between ACT UP and having a life. I never had time for other interests.

It really did suck up my time and didn't leave me time to plot out my future.

It was very consuming. I had no separate life.

I would have focused on career earlier.

\section{Difficult aspects}

We asked, "what were the most difficult aspects of being an ACT UP member" (without a checklist). Table 5 provides illustrative examples of each.

Half of the members' responses cited Conflict. "Screaming at each other. People go for blood. They can be nasty - how people treated each other was awful," and "so many people were a pain in the ass, all the P.C. spirit." The meetings themselves were often described as agonizing to endure: "tedious meetings: democracy is messy." And "lack of negotiating, no effort at consensus, just shouting down differences."

Themes of Loss and death were often reported. Members who had died during the previous week were remembered at the beginning of each meeting. Deaths of partners, friends, and ACT UP acquaintances were 
painfully common. As one man put it, "When I was 20, I went to 30 funerals." One respondent spoke of "an endless well of sorrow; death and death: watching so many people get sick and die."

Finally, there was the long-term impact of the Time commitment. Between Monday meetings, committee meetings and related work, smaller "affinity" groups, and trainings for demonstrations as well as the demonstrations themselves, there was little time left over for personal and vocational activities. Some noted the effect on their career trajectory: "My involvement in ACT UP stopped my career because I was so involved in ACT UP.; "it was a time sink, not moving on with life."

Other negative aspects of ACT UP that several respondents mentioned cliques: "There were the cool kids, the cooler kids, and the coolest kids. I wasn't one of them." Others were discouragement: "We were doing everything in our power to save the people we loved but were unable to save them"; and exhaustion: "you can't keep that level of anger up your whole life."

\section{Participants' Concluding Observations}

At the end of the interview, we asked if there was anything the respondent wished to add; everyone had something to say. While we can't begin to capture the richness and diversity of their comments (here and elsewhere in the interviews), some themes that did not emerge earlier include the following:

"When I meet young people today, I feel badly that they didn't have the experience where they gave themselves passionately and completely to something, as I did in ACT UP. For two years it was my life."

"I believe the people in ACT UP experienced something extraordinary. When people fight the good fight and the fight stops, there's a problem finding meaning in ordinary life and rejoining the real world which really isn't compelling."

"I've always thought there was something wrong with me and that others have moved on over their grief and I have not. I get annoyed about people pushing resilience. I get it but if you're not feeling so resilient, hearing that is not helpful.

"The [dominant] members were upper class mostly white men who lived in a community of privilege and felt it was their birthright. And when that was taken away, they had the resources and wherewithal to fight back."

"Underneath the bravado there was a loving community in ACT UP... Something about being with other people who are fighting for their lives gives a whole different tone to the movement, which is missing when activism is for the benefit of others."

\section{DISCUSSION}

In its first five years, ACT UP/NY achieved a major impact on public opinion, government action (e.g. the Ryan White Comprehensive AIDS Resources Emergency Act, August 1990), and the design and conduct of clinical trials sponsored by federal agencies and pharmaceutical companies. This influence, together with its ability to galvanize public attention through vivid demonstrations, established ACT UP an extremely effective new social movement. It can also be argued that subsequent progress such as expansion of health care, patient education, empowerment, and collaborative decision-making were positively influenced by ACT UP. As Epstein noted, "the AIDS movement is...the first social movement in the United States to accomplish the mass conversion of disease 'victims' into activist-experts" (1995: 414).

In his 1989 article, "Silence, Death, and the Invisible Enemy: AIDS Activism and Social Movement "Newness," Gamson points out the unique challenges confronting ACT UP, which was waging battles on two fronts: one with a clear, visible enemy - government agencies and drug companies, and the second with an abstract, invisible enemy - the stigma and "abnormality" associated with gay identity. He suggests that understanding ACT UP, and social movements like it, "hinges on the answer to a pivotal question: Who is the enemy?"(p. 357). In retrospect, one might argue that ACT UP succeeded on both fronts, despite the existing tension between AIDS politics and Gay politics.

Even considering the particular circumstances of ACT UP in the late 1980s, its strategies are generalizable. Those engaged in addressing contemporary social issues, such as gun control and the opioid epidemic, may find the strategies and activities of ACT UP's members useful, as noted in a recent New York Times editorial ("An Opioid Crisis Foretold," New York Times 4/18/18).

In 2011, Manganiello and Anderson prepared a report, "Back to basics: HIV/AIDS advocacy as a model for catalyzing change" (2011), with similar conclusions. They interviewed a broad range of participants, including federal government officials (both administrators and scientists), as well as several prominent ACT UP members. Their goal was to understand how and why ACT UP had such influence. They proposed five features (p. 8): attention (demonstrations); knowledge and solutions (e.g., Treatment and Data Committee); community (including HIV+ and HIV- members, and the friendship networks as well as activist work); accountability (follow-up); and leadership (in government as well as within the activist community). They emphasized that protests and 
demonstrations are effective in gaining public attention, but do not in themselves cause change. The critical ingredients include identification of systemic problems at both the political and scientific level, self-education about change strategies, and articulation of proposed solutions delivered by "informed stake-holders" (p. 12). While acknowledging the "unique moment in time when the illness and death of thousands of people catalyzed action [AIDS deaths in the 1980's]," they argue that the AIDS activism of that time "is instructive for advocates today. It also provides hope and shows what is possible even in the face of seemingly insurmountable odds. Change is possible" (p. 3).

Participation in the early years of ACT UP was intensive, partly because of the limited communication options then available (mail, phone calls, photo-copied hand-outs, face to face meetings) as well as the immediacy of the AIDS crisis and the imminence of disease and death both to individuals and the larger affected community. For many members, ACT UP was the focus and center of their lives, every day. In our study, becoming part of an accepting activist community with a shared goal of survival (as individuals and as a community) was a prominent reason for joining ACT UP. Other reasons included emotional aspects including anger and connection with others or camaraderie. This is consistent with Gould's (2002) conclusions after interviewing ACT UP/Chicago members that the "emotion work" of social movements is vital to their development and persistence. She describes the "emotional common sense" of turning grief into anger, and anger into action. She summarizes as follows:

Activists' transmutation of pride, responsibility, and shame, along with their tethering of grief to anger, provided thousands of lesbians and gay men with a new emotional common sense that helped to animate and sustain their support for militant AIDS activism (p. 189).

The sense of community, serving as an agent for change, was identified as a major benefit of membership, and is the main characteristic that its members most miss in retrospect. A central feature appears to be group affiliation and support, as articulated in Junger's (2016) concept of "unit cohesion," derived from observations of military combat. As Halkitis (2013) noted, coming together "provided social support and cohesion and a buffer against isolation, loneliness and potential despair" (p. 117). More generally, activism as such has been found to contribute to psychological well-being (Klar and Kasser, 2009).

Social media, e-mail correspondence, list-serves, tweets and video-conferencing are tools of connection people now employ. Among contemporary activists, some work largely alone to protest particular conditions, circumstances, or events. Others gather for ad hoc protests, often without forming stable networks (e.g. Washington DC marches). As such, participants are less likely to have the benefits of long-term connectedness, friendships, and cohesion. The time and intensity that ACT UP members devoted to their mission in the early years may be replicated infrequently today. However, new communication opportunities can be applied to political movements.

An example of the integration of existing and innovative strategies is provided by students who survived the Parkland (Florida) shooting massacre at Marjory Stoneman Douglas High School in February 2018. In the aftermath of extensive news coverage during which surviving student spokespeople were interviewed, a group of these students employed a hashtag, \#NeverAgain, organized a march on Washington in March 2018 ("March for our Lives,") to promote gun control legislation, and went on a cross-country bus tour to 75 cities (New York, 2018) to register young voters.

To these established methods, used by other direct actions groups such as ACT UP, the students used enhanced communications. Its leaders have six-figure Twitter followers. A group member asked a local t-shirt designer (and former student) to design a t-shirt, (to sell in order to help fund the tour). The t-shirt had an American flag (like that of the NRA) and a QR (a variant of bar code); when viewers click on it using a special app, it goes directly to an on-line voter registration page now available in 38 states. The intermediate goal of registering students to vote is in the service of their major focus - regulation and restriction of guns. The Parkland students reported that by August 2018, 10,000 people had registered as a result of t-shirt sales (LeVine, 2018).

\section{Study Limitations}

One limitation is sample composition. We used personal and internet networks to contact potential participants, as described above. However, the sample cannot be considered representative of the membership in ACT UP's peak years since there was no master list of members, a substantial portion of members have died, and there is no systematic method for contacting surviving members even if we knew who they were. However, the demographics do resemble those reported by Elbaz (1990). He distributed a survey to 500 members at Monday ACT UP meetings in June and July of 1989 , with a $90 \%$ response rate. In brief, $80 \%$ of members were gay white men, more than $60 \%$ were college graduates, and were predominantly young (25\% were under age $26,50 \%$ were ages $26-35)$. When they joined ACT UP, $25 \%$ of the men knew they had AIDS. Professionals and artists constituted nearly $50 \%$ of the membership. Another possible limitation is that former members who were not thriving were less likely to participate, although some with current psychological problems did so (Rabkin, 2018). 
Another limitation stems from our choice to cover multiple areas of inquiry, including times before and after 1987-1992, as well as the nature and extent of experiences in these ACT UP years. Consequently, we could not investigate a given area in depth. For example, we didn't ask in detail about the extent to which their ACT UP experiences influenced participants' politics, careers, or subsequent activism, although we did elicit broad patterns.

From a methodological perspective, the approach of the questionnaire was geared towards areas concerning mental health, which reflects our backgrounds in psychology (MMc, MRF and JR), and specifically our interest in the questions posed by the late Spencer Cox, a prominent member of ACT UP, who suggested possible negative consequences of community activism ("Living on the Edge: Gay men in mid-life, and the impact of HIV/AIDS," Medius Institute for Gay Men's Health, unpublished). This perspective should be kept in mind when considering the results and conclusions of this report.

In summary, although ACT UP/New York 1987-1992 was characterized by circumstances and communication methods specific to those times, we think lessons can be learned by social movements today: sustained local networks, publicity-generating attention to the agenda, meticulous preparations for actions and public relations, and educated recommendations for solutions and sustained follow-up. Finally, inclusion of voices of those whose welfare is at issue can be a powerful tool for change.

\section{ACKNOWLEDGEMENTS}

We thank the participants for their time and willingness to share their experiences and memories from ACT UP, and also members of our Advisory Board. We would also like thank Erin Timperlake for her assistance managing the data set and coding qualitative responses, and Andrew Miller for his insightful comments and skillful editing of a draft of this paper. Funding for this research was provided by grants from amfAR, The Foundation for AIDS Research and Broadway Cares/Equity Fights AIDS.

\section{REFERENCES}

Crewe, T. (2018). Here was a plague. London Review of Books, 40(18), 7-16.

Crimp, D. with Rolston, A. (1990). AIDS Demo Graphics (p. 28). Seattle: Bay Press.

Cvetkovich, A. (2003). An archive of feelings: Trauma, sexuality, and lesbian public cultures. Durham: Duke University Press. https://doi.org/10.1215/9780822384434

Editorial Board. (2018). An Opioid Crisis Foretold. New York Times. Available at: https://www.nytimes.com/2018/04/21/opinion/an-opioid-crisis-foretold.html (Accessed 14 August 2018).

Elbaz, G. (1995). Beyond anger: the activist construction of the AIDS crisis. Social Justice, 22(62), 43-76.

Epstein, S. (1995). The construction of lay expertise: AIDS activism and the forging of credibility in the reform of clinical trials. Science, Technology, \& Human Values, 20(4), 408-437. https://doi.org/10.1177/ 016224399502000402

Evans, E. M. (2016). Bearing Witness: How Controversial Organizations Get the Media Coverage They Want. Social Movement Studies, 15(1), 41-59. https://doi.org/10.1080/14742837.2015.1060158

France, D. (2016). How to Survive a Plague. New York: Knopf.

Gamson, J. (1989). Silence, Death, and the Invisible Enemy: AIDS Activism and Social Movement "Newness," Social Problems, 36(4), 351-367. https:/ / doi.org/10.1525/sp.1989.36.4.03a00030

Gould, D. B. (2002). Life during Wartime: Emotions and the Development of ACT UP. Mobilization: An International Journal, 7(2), 177-200.

Halkitis, P. N. (2013). The AIDS generation: Stories of survival and resilience. Oxford University Press. https://doi.org/10.1093/acprof:0so/9780199944972.001.0001

Hill, C. E. (2012). Consensual qualitative research: A practical resource for investigating social science phenomena. American Psychological Association.

Junger, S. (2016). Tribe: On homecoming and belonging. London: Hachette UK.

Kayal, P. M. (1993). Bearing witness: Gay Men's Health Crisis and the politics of AIDS. Boulder: Westview Press.

Klar, M. and Kasser, T. (2009). Some benefits of being an activist: Measuring activism and its role in psychological well-being. Political Psychology, 30(5), 755-777. https://doi.org/10.1111/j.1467-9221.2009.00724.x

LeVine, S. (2018). Parkland students blend QR and fashion to register voters. Available at: https://www.axios.com/2018midterm-elections-march-for-our-lives-qr-voter-registration-87556a63-da00-4083-a690-45d1e9d1ceca.html (Accessed 14 August 2018).

Manganiello, M. and Anderson, M. (2011). Back to basics: HIV/AIDS advocacy as a model for catalyzing change. Strategists and Faster Cures and HCM Strategists, 127. 
Miller, L. (2018). David Hogg, After Parkland. New York Magazine. Available at: http:/ / nymag.com/daily/intelligencer/2018/08/david-hogg-is-taking-his-gap-year-at-the-barricades.html (Accessed 14 August 2018).

Rabkin, J. G., McElhiney, M. C., Harrington, M. and Horn, T. (2018). Trauma and Growth: Impact of AIDS Activism. AIDS Research and Treatment, 2018, Article ID 9696725. https://doi.org/10.1155/2018/9696725

Rimmerman, C. A. (1998). ACT UP. In Smith, Raymond A. (Ed.), Encyclopedia of AIDS: A social, political, cultural, and scientific record of the HIV epidemic (pp. 36-40). Abingdon-on-Thames: Routledge.

Slezak Karas, L. (Ed.) (2008). ACT UP New York Records, Manuscripts and Archives Division, The New York Public Library.

Smith, R. A. and Siplon, P. D. (2006). Drugs into bodies: Global AIDS treatment activism. Santa Barbara: Greenwood Publishing Group. 